\title{
Strategies For Mass Customization
}

\author{
Dennis Pollard, California State University - Fullerton \\ Shirley Chuo, American Intercontinental University \\ Brian Lee, Hanyang University, Korea
}

\begin{abstract}
Mass customization allows firms to produce only things their customers want (or produce after they have orders in hand). This approach, make-to-order, brings many benefits to firms in terms of cost and profit because of lower inventory levels, maximum sales, elimination of material waste, flexible production and, most of all, customer satisfaction. However, mass customization may not be the panacea for all organizations. While some companies are very successful with mass customization, others are not. This paper illustrates that mass customization strategies depend on an understanding of the conditions in each industry.
\end{abstract}

\section{INTRODUCTION}

$\mathrm{n}$ his book "Markets of One - Creating Customer Unique Value through Mass Customization", Joseph
Pine, II wrote:

Mass Customization calls for flexibility and quick responsiveness. In an ever-changing environment, people, processes, units, and technology reconfigure to give customers exactly what they want. Managers coordinate independent capable individuals, and an efficient linkage system is crucial. Result: low cost, high quality, customized goods and services.

Mass customization requires the operating network have to be flexible or dynamic because the original purpose of mass customization is to adapt one-to-one; its goal is to allow customers to design needed products themselves. With that goal, the demands of customers become predictable. To be flexible, operations should be a system of units or modules; each of them is typically a task or process.

Quick responsiveness is a broad concept that is evaluated by some criteria such as capability of offering exactly the features that customers need, delivering on time as promised, supplying the quantity as contracted, etc.

Very importantly, mass customization demands that besides satisfying at most customers' demands, operation cost (thus price) and the quality of products must be improved. It is unacceptable if mass customization results in a big additional cost that is out of acceptable price (the failure of P\&G' coffee product described later illustrates this point).

\section{Core Process -"Build-To-Order"}

Mass customization goes around the concept "build to order". Build to order" is certainly the solution for mass customization when the company does not know demands until having orders in hand. As a result, production just happens after that. In the past, with the concept "build to forecast" or "build to stock", production was based on demand forecast. The drawback of demand forecast is the forecasted information is not exact since it relies on past numbers and many assumptions, thus the outputs of production cannot match the highly different demands of mass customization. The gap between production on forecasted information and real demands burdens large costs such as high inventory cost (components and finished products), material and other resource waste, cash flow decline, etc. on operating results. In mass customization approach, products are just built after the company has the orders in hand with the exact quantity and quality required. In addition, the slight variations in many products requires additional sophistication relative to a more educated and demanding current consumer in this Global Economy. 


\section{Advantages Of Mass Customization}

- $\quad$ Maximized market share by maximizing customers' satisfaction and number of customers.

- Cut cost of inventory and material waste: materials and inputs are pushed into production just in time. Also, very low inventory of finished products because of production to orders, not produce to stock.

- $\quad$ Increase cash flow: Lower inventories, prepayment (thus lower receivables)... increase cash flow.

- Shorten time of responsiveness (accumulative time from receiving orders to delivering): organization structure and flexible manufacturing in mass customization allows the company to adapt to different demands rapidly.

- $\quad$ Ability to supply a full line of products or service with lower costs: the purpose of mass customization is to differentiate products to particular demands, resulting in broader product lines of the company and a much lower risk of obsolete inventory.

\section{Approaches To Mass Customization}

Joseph Pine, II identifies four approaches to apply mass customization:

- $\quad$ Collaborative customizers: these organizations establish a dialogue to help customers articulate their needs and then develop customized outputs to meet these needs. Levi's is an example of this approach. The company uses a computer system in its shops with plants. Customer wants (size, model, color...) will be measured at Levi's shops, and then this information will be computerized and sent to Levi's plant to produce a custom-fitted pair of jeans. Nike and Dell are two other examples of this approach.

- $\quad$ Adaptive customizers: customers buy a standard product but they can modify it by themselves based on their needs. For example, Microsoft offers a package of software designed to run all activities of small businesses. But if a buyer (a small business) wants, for instance, to add more accounting functions into the package. it allows doing that because it uses a popular programming language that can be used by other programmers.

- $\quad$ Cosmetic customizers: these companies produce a standard product but present it differently to different customers. For example, Planters packages it peanuts and mixed nuts in a variety of containers on the basis of specific needs of its retailing customers such as Wal-Mart, 7-Eleven, and Safeway.

- $\quad$ Transparent customizers: These companies provide custom products without the customers' knowing that a product has been customized for them. For example, an online computer might track how each customer uses its service and then suggest additional features that the customer may find useful. In a similar fashion, Amazon.com provides book recommendations based on information about past purchase.

\section{Key Success Factors}

Mass customization means that manufactures are able to customize products on large scale and at high speed, as well as lower cost. But how can they do that? Most experts agree that mass customization is successful or not depended on some key factors as below:

Modular product design: each module retains operational authority for its particular process (or job). Without this, product customization would be very difficult in terms of time consuming, slow, and very costly. In modular product design, products are designed under some modules or processes which enable any types of customization. For example, The Boeing Co., classified thousands of parts, components, options, and documentation for its aircraft as standardized, configured to a finite set of options, or customized. This system enables the company to streamline ordering, engineering, and manufacturing. Modular product design can be built up based on the models "project shop" or job shop of required throughput.

\section{Requirements:}

- $\quad$ Readiness of inputs when needed (this requires an effective supply network), skillful, highly educated employees with excellent technical qualifications. 
- $\quad$ High standardization of components.

- $\quad$ Relevant organizational structure that enhances the coordination among modules.

Benefits:

- $\quad$ Maximize the number of standard components used in all forms of the products

- Shorten time of production: because all modules can be done at the same time (not in a sequence), so the time required for production is reduced significantly.

- $\quad$ Easily diagnose production problems (quality, defect products, etc.), and thus isolate potential quality problems under special controls.

Flexible manufacturing process: mass customization generates a variety of different products. That requires the manufacturing system be highly flexible. This factor reflects capacity of production in terms of adaptation to high difference of products without lead time, cost of changing the system, and regardless of small volume of ordered products. Often if a company effectively organizes its modular product design, the manufacturing system is flexible, consequently it delivers the variety and lower cost features in a timely manner.

Sophisticated order management: mass customization is based on profound understanding of customers' demands. Since individual demands are extremely different, the order management system is crucial to enhance the relations between customers and the manufacturer. It (the system) provides a wide range of works such as open profiles of each customer in a database, manage the sheer volume and breadth of numerous customers and customer orders, and by keep track and allowing easy access to the status of each order at anytime.

\section{Requirements of the factor:}

- $\quad$ Close relationship with customers

- $\quad$ High capacity of the system to handle a huge amount of information (database, transactions, etc.)

- Deep integration along the value chain (through the order management system): the high degree of customer involvement in product configuration means that sales, marketing, distribution, manufacturing also need to know accurate information of customer requirements.

A typical example of an order management system is that of Dell Computer. The website (www.dell.com) allows customers interact directly with the company to show up their demands. Customers, after choosing satisfactory products from many options, just click on the screen to order those products. Because of the integration of all Dell's departments from inventory \& manufacturing, to sales, marketing, finance, billing, logistics, etc. through the website, the order is processed by all those departments at the same time, the outcome is that the customers can know immediately all terms of the purchase in a very rapid and accurate fashion.

Integrated information system: the role of information systems in a mass customization company is highly critical for success. The main characteristic of mass customization --the uncertainty of demands -- plus the requirements of flexible manufacturing, short lead-times, exact adaptation, and quick responsiveness, call for an efficient information system to ensure the flow of information is smooth and accurate between customers and manufacturers, also among the company's divisions. To manage that kind of minute-to-minute, multiple-to-multiple decision making, a decision-support system that integrates information from all participants in the entire organization, as well as between customers and the manufacturer is essential.

Postponement of assembly: as mentioned above, the uncertainty of mass customization demands is a big obstacle for production in terms of operating cost. The perspective of hibernation of the operation system when demands are lower than production capacity is a fear manufacturers have because a shutting-down of operation weigh heavy on fixed assets, inventory overhead, maintenance, working salaries, etc. However, the company can eliminate those costs if it has solutions to postpone the operations when demand volume is low. However it can still ensure that the operation will restart quickly if demands suddenly goes up. A solution to solve this challenge is to use outside production. For example, Nike does not produce shoes itself, its partners in Asia are in charge of 
production through contracts. Nike's investment on machines for assembly, material inventory, management of workers, plants, etc. is basically zero. So, when demand is going down, Nike just adjusts the contract delivery schedule. By that way, the fixed costs are no longer burden to Nike. For some products, whose differentiations are base on packaging, the company can outsource the steps of packaging to reduce the uncertainty of demand fluctuation.

\section{STRATEGIES TO PURSUE MASS CUSTOMIZATION}

\section{Differentiation}

This strategy is a basic requirement if the requirement is to apply mass customization. The competition on differentiation must be intensive. Individual demands may be very different from each other, so mass customization means that we can differentiate our products to changing demands. Also, in the view of industry, if competition among companies is the try to meet needs of each person, in that context a mass customization company owns a competitive edge, since it is capable of providing wider options of products to customers than its competitors.

Reality proves that, definitely, mass customization just happens to be most effective based on highly differentiated products like computers, electronic machines, clothing, shoes, etc. Some products whose competitive advantage does not base on high differentiation are not able to apply mass customization; they are, for examples, electricity supply, commodities such as gas, wheat, and most other non-differentiated products.

\section{Lower Cost}

Low cost is another basic requirement of mass customization. It seems ridiculous to say that differentiation and lower cost can live together, but it is reality. In the past, with mass production approach, lower cost comes from the effectiveness and efficiency of production, including the economies of scale. But in the mass customization approach, lower cost comes from lower inventory, higher cash flow, customer satisfaction maximization, quicker responsiveness, etc. In addition, mass customization the company does not get lower cost itself by economies of scale at present, but it still obtains these economies by outsourcing production to its supplliers.

Today, customers are very fastidious. They, on the one hand, want to choose a product fitting to their exact needs; on the other hand, require a just a slightly higher price than that of non-customized products. Mass customization must satisfy both. The failure of a product of $P \& G$--coffee--proved that point. P\&G sells coffee through the website that allows customers to blend coffee based on their taste However, the price of a customized coffee bag doubles or even triples normal and of course customers are unwilling to pay for that much higher premium price.

The combination of differentiation and lower cost often directs a mass customization company toward the strategy of best value provider. Dell, Boeing, Nike ... are typical companies that follow the strategy of best value providers who provide highly differentiated products with very competitive prices.

\section{Supplier Relationships (Or Alliance) Outsourcing}

As mentioned above, two of the key success factors are "flexible manufacturing system" and "postponement of assembly". To enhance these two factors, the strategies of supplier alliance and outsourcing are options, but why?

The flexibility of manufacturing depends much on the supply network. The frequent changing of production in mass customization results in the fluctuation on inputs procurement. So a mass customization company has to build up strong and broad relationships with suppliers to reduce the risk of input fluctuation. More detail, a characteristic in mass customization production is that inputs are pushed into production just-in-time. Justin-time (JIT) is possible only when suppliers know clearly about information such as production plans, current material demands, inventory in hand of producers, etc. In short, to be flexible in manufacturing, the mass 
customization companies, somehow, must own a strong supply network that can be achieved by alliance with key input suppliers. A malpractice of many producers in mass customization is that instead of using JIT and supplier relationship to secure input's safety, they stock inventory for every combination that customers could order, an approach that ends up saddling the manufacturer with a huge amount of money in excess inventory and unneeded warehouse cost.

The postponement of assembly, or even the flexibility of manufacturing, can be enhanced by outsourcing strategy. Outsourcing allows a mass customization company to avoid large investments on fixed assets that can lead to high fixed costs, thus decrease the risk of fixed cost leverage. Today, very often, many companies pursuing mass customization use the third parties in the entire process or some key steps of production. Nike as exemplified above is one example of outsourcing the entire production, Starbucks procures coffee beans from independent coffee growers. This is an example of outsourcing material growing, or outsourcing delivery service is the practice followed by many companies.

\section{Forward Integration Distribution Network Of Customer Relationship Developments}

Mass customization needs to communicate directly with end-users, or at least information between the company and end-users is direct and not distorted by intermediaries. To understand exactly what they want, a "sophisticated order system" is established ensuring that demands of customers are recognized immediately and accurately. In this order system, the distribution network becomes shorter, intermediaries such as wholesalers, retailers are cut down or minimized. More important, the distribution network must be controlled by the company. It means that a mass customization company has to invest money to integrate a distribution network into its value chain.

The easiest way to communicate effectively with end-users is to develop an online distribution website. Dell, IBM, P\&G have their own websites to aid in product sales and services. For traditional distribution (through outlets), it is perfect if a mass customization company sets up its own distribution network, thus full control of customer relations, A drawback here is that it is expensive. The alternative is to support and integrate outlets' information systems with that of manufacturers. For example, Levi's set up an information system link to all outlets' computers to its plants, updated orders go directly to plants to be produced. Wal-Mart also has a very effective system for collecting data for warehouse reorders being transmitted direct by computer to supplier warehouses.

Firms that are not able to integrate their distribution network cannot successfully apply mass customization.

\section{Organization Structure}

"Modular product design" and "flexible manufacturing process" require a particular organization structure. The general tendency is that organizational hierarchies with many levels are definitely not relevant for a mass customization company. The organization structure should be flatter with fewer levels, and creates a freedom for the coordination among processes (modules). It focuses on a high degree of cross-functional integration and employee participation. This results in a much higher degree of decentralization in decision making. Besides, the structure is open to suppliers as well as customers because they (suppliers and customers) are considered extensions of the organization.

Based on above requirements, the organization structure should be as follows:

- $\quad$ Management focuses on three parts: supplier relation, customer relation, and resource management

- $\quad$ All departments integrate along value chain

- Information system links organization's parts, and also provides the connection with suppliers and customers 


\section{CASE STUDY \#1}

\section{Failure Of The Automobile Industry In Mass Customization Practices}

Mass customization as mentioned above is not feasible for all companies or industries. This is very clear since its four key success factors require the availability of the strategies discussed above. Not all companies can follow those strategies, while the lack of just one of those strategies can make the practice of mass customization unsuccessful. The article "false promise of mass customization- published in The McKinsey Quarterly has beaten against the hopes of car makers to apply mass customization. We will get into this example to understand what keep mass customization in car industry far away successful practice.

Giant auto companies, such as BMW, Ford Motor. GM in the US and Toyota in Japan, have paid much effort to pursue mass customization some years ago, but the successful results they obtained so far is very limited, and the future is not bright (of mass customization) at all.

First of all, the forward integration strategy is limited in the car industry. Selling cars through dealers is the main distribution channel of any carmakers. Setting up their own dealers is impossible because of huge investments and the prohibition of most US states not allowing manufacturers to sell cars directly to customers. Car dealers, most of them owned by actually one entrepreneur, have strong influence on manufacturers. In addition, dealers have rights to get free financing for the first 10 days of inventory on their lot. They prefer large stock to show variety for consumers to chose from a wide array of floor stock. This is opposite of mass customization. A dealer said quote: "A large number of cars on my lot show I am healthy, open for business, and offering wide choice. Why should I trade that in for two demo cars in a dinky showroom?" So it is hard for carmakers to pursue low inventory and adapt to individual demands since dealers think in a very reverse way from auto manufacturers..

Weak connection between carmakers and customers also aids in the failure of mass customization in the car industry. Although carmakers can set up websites or other information channels to improve their relationship with customers, a survey shows that they (customers) place greater value on the dealer's ability to help them decide on options of the cars they want to purchase. This means that buyers' information does not go directly to the carmakers, as customers rely on the dealers, making difficulty for demand adaptation to custom features.

Achieving the strategic manufacturing flexibility required for mass customization would require many operational changes. For example, some steps of car manufacturing such as painting, must be done inside, and not by outsourcing. Customers like to choose the color of their cars, but paint shops at car plants run in batch mode to cut cost and to minimize the emissions and waste that are generated as paint guns receiving new colors are flushed. In addition, it is hard to set up "build to order" because carmakers might have to carry a range of modules (some of which may vary slightly in color, choice of fabric, or even an individual part). Modules could involve greater redundancy and within the supply chain than do non-modular components; modules also take up more floor space than so loose parts and are more costly to ship. Or in other words, production in the car industry is still in the mass production mode, and has not changed to mass customization yet. Thus it is not flexible enough to adapt to demands in mass customization in an efficient manner.

Cost of mass customization is a big problem carmakers face. As an example, if a customer orders an option, such as a certain style of sunroof, that is installed during an upstream manufacturing stage and wasn't already part of a vehicle in inventory or production, the automaker would have to interrupt the production flow, and thus increase the price. Also, an additional price of about $\$ 100$ to $\$ 200$ charged to an option of paint may cause the customer to cancel the option. Another cause of cost problems is that labor unions in the car industry would oppose the external assembly of modules. Managers throughout the OEM organization and the value chain, would at least initially resist incentives that pull parts and cars through the system in response to customer demand instead of pushing them through supply and assembly to dealerships. This obstacle makes it difficult for carmakers to do outsourcing,. Flexible manufacturing cuts cost when demand is low. The cost problem reflects a reality that customization in the car industry is applied in a limited manner in luxurious cars only, where price is not inelastic. 


\section{CASE STUDY \#2}

\section{Success Of Computer Industry In Mass Customization Practices}

The computer industry seems enjoy a much greater advantages of mass customization. In the last six years. Dell and HP are pioneers to apply mass customization and have obtained dramatic success. The followers such as IBM, Cisco, and so on also have oriented their business toward mass customization. Below is a break down of what Dell has done to pursue mass customization, with the perspective of strategic management.

As one of the world's leading direct computer system companies and a premier supplier of technology for the internet infrastructure, Dell is widely recognized for its efficient build to order business model. Customers across the globe can order customized computers or servers through the dell.com website and only after the orders are placed, then the computers are built in a Dell factory to customer specifications

In Dell, the value chain includes three parts: Supplier relationship management (SRM), Supply chain management (SCM), and Customer chain management (DCM).

\section{Dell Success}

The extremely flexible manufacturing of Dell, in which "build to order" is the rule, require components are pushed into production just two hours behind receipt of customers' orders. Dell actually does not stock any inputs. To obtain those, Dell launched valuechain.dell.com, a secure extranet that joins Dell with its suppliers. At any time, assigned suppliers can access into the website, reach "Factory Planner" and "Supply Chain Planning", to view Dell's reports on production plan, material demand, material quality, negotiated and forecasted cost reports. With that information, each supplier knows what to do to guarantee sufficient inputs for Dell's production. In addition, suppliers are required to have inventory hubs (material stores) near the Dell's manufacturing plants to deliver the required materials in shortest time.

Presently, Dell has a network of about 200 suppliers worldwide. Dell has paid much attention to evaluating capacity of suppliers before developing relationship with them. Once accepted, suppliers become an part Dell organization. Manufacturing plants of Dell are located worldwide and under a principle: having materials in close proximity to its factories. In reality, manufacturing plants are custom assembly plants.

\section{Dell Direct Customer Sales}

Instead of distributing via retailers, Dell set up its own the website dell.com to sell computers directly to end-users. In this manner Dell is capable of receiving customer demands accurately and quickly. Customers can customize their computers through the website, and the transaction is done in very short time and paperless. After that, customers are still able to connect through the website to check the status of the orders, as well as gets postsales service. With this way of distribution, Dell cuts much costs paid for intermediary channels, avoids distortion of information through intermediaries, provides a wide range of customized products to customers. It acts with effectively zero finished goods inventory and zero inventory carrying costs.

\section{Dell Processing Strategy}

Although Dell products are highly customized and excellent quality, the prices are very reasonable. Why? First of all, by pulling only the materials it immediately needs, Dell has been able to cut down inventory (the time of materials staying in inventory is just 7 hours, comparing to several weeks of competitors), thus it has about $4 \%$ or 5\% lower cost of materials. Second, Dell does not produce products to stock: finished products are shipped immediately after production. Further, with the direct model. Dell's customers must pay prior to receiving products that benefits Dell much in terms of capital use. Use of credit cards on the internet virtually results in zero bad debts and sales of approximately fifty million dollars per month. 
Service provided online also is a competitive advantage. Differing from its competitors, Dell does not pay much money to set up service centers as customers can get almost services through website freely or with very small fees through the website, either freee of charge or very minimal fees.

\section{Outsourcing at Dell}

Dell follows a strategy of outsourcing subassemblies, standard and non-configurable components, however Dell prefers to keep control on the key final assembly and configuration processes. For essential components, Dell looks for suppliers who have global capabilities such as Intel, IBM, Sony, Toshiba, etc. For unimportant components, Dell deals with local companies (most of them in Asia), who can supply low cost inputs. Dell uses the strategy "standardize to be customized" for all components procured. Because the modular product design and flexible manufacturing require components are highly standard, components must be standardized in term of quality, but they are diversified by many options (memory capacity, colors, sizes, etc) to be customized if more specific individuality is needed.

\section{CONCLUSION}

After breaking down the core success factors, and the strategies needed to pursue mass customization, were analyzed in examining the case studies of both automotive and computer industries it appears that mass customization cannot be useful for all industries or companies. Only those who can achieve above key success factors may be successful in mass customization.

Below are more detailed questions that should be answered before deciding whether to follow the mass customization strategy:

- Do your products compete on high differentiation?

- Can we maintain or even reduce costs through mass customization? Because mass customization means that the company customizes the products to the mass market. The price criterion is important here.

- $\quad$ Can a strong relationship develop with suppliers and thus adopt an effective supply network?

- $\quad$ Can integration of the distribution network be achieved at most important stages?

- Is it possible to outsource components to aim at enhancing postponement of assembly when low demand is in the market?

- Is the ability to communicate directly with customers?

- $\quad$ Is organization of production by modules (not Flow job) possible?

- $\quad$ Is manufacturing flexible enough to satisfy individual demands (low volume, different features...) in shorter time and less cost than before?

- Do capabilities exist which enable the company to apply an information system which integrates all divisions and employees, even suppliers and customers into a united body? Is the organization structure ready for mass customization, or must changes occur before adopting mass customization? (The organization must be flat, cooperative, open to outside).

If all questions are answered "Yes", then one may proceed with mass customization. Be careful with any questions that are not answered clearly\} because any of them, if not satisfied, may make a mass customization strategy unsuccessful.

\section{AUTHOR INFORMATION}

Dr. Dennis Pollard has a PhD from Claremont Graduate University. He is President of P.S.C. International, an international trade development company working primarily with South East Asian Governments. Currently, Dr. Pollard is advising the Royal Thai Government on a strategic trade program for future bilateral trade with the USA. $\mathrm{He}$ serves on the faculties of several universities in Southern California. Dr. Pollard has over 30 years experience in corporate sales and marketing. 
Dr. Shirley Chuo is a full time business faculty member at American Intercontinental University online, where she teaches courses within the Organizational Psychology Discipline both in the Bachelor and Masters Programs in Business Administration. Dr. Chuo has taught for Pepperdine University in the MBA and the BA business programs. She has also taught for Loyola Marymount University. Additionally, she also serves as a committee member for reviewing doctoral candidates at Argosy University. She has also had consulting experiences within the industry and has led training sessions at numerous Fortune 500 companies such as Honeywell, AT\&T and Time Warner. Her expertise lies in the domain of employment law, change management and executive coaching. She has over 5+ years teaching experience and enjoys developing managerial skills in business leaders. She also serves on the advisory board to the business department and has held the title of Assistant Treasury to Sandpipers, a 75 year old non-profit organization helping provide community assistance and scholarships to disadvantages youths. Dr. Chuo has two articles published in the International Business and Economics Research Journal and has won the best paper award in 2005 and 2006 at the Clute International Business and Economics Research Conferences. Dr. Shirley Chuo belongs to Society of Human Resource Professionals, Los Angeles Organizational Development Network and Academy of Management. She has earned her bachelor's degree at Colgate University and her Masters degree at Pepperdine University both in psychology. Her doctorate degree is in the field of Organizational Behavior from Alliant University.

\section{REFERENCES}

1. Mani Agrawal; Glenn A. Mercer; and T. V. Kumaresh. The false promise of mass customization, The McKinsey Quarterly, Summer 2001 p 62. Available online: http://webS.infotrac.galegroup.com/itw/infomark/563/672!36168")81w5/Purl=rcl BCPM 0 A77 578809\&dyn=6 $\operatorname{xrn} 270$ A77578809?sw aep=csuf main .

2. Edward Feitzinger; and Hau L. Lee. Mass customization at Hewlett Packard: the power of postponement. Harvard Business Review, Jan-Feb 1997 v 75, nl, p. 116(6).

3. John Liechty; Venkatram Ramaswamy; and Steven H. Cohen. Choice menus for mass customization: an experimental approach for analyzing customer demand with an application to a Web-based information service. Journal of Marketing Research, May 2001 v38, i2, p 183(14).

4. Briance Mascarenhas; Alok Baveja; and Mamnoon Jamil. Dynamics of core competencies in leading multinational companies. California Management Review, Summer 1998 v40 n 4, pl 17(16).

5. James H. Gilmore,II; and B. Joseph Pine, II. The four faces of mass customization (includes related article on marketing to new markets). Harvard Business Review, Jan-Feb 1997 v 75 n I p 91 (11).

6. B. Joseph Pine, II; Bart Victor; and Andrew C. Boynton. Making mass customization work (includes related article on Bally Engineered Structures Inc.). Harvard Business Review, Sept-Oct 1993 v 71, n 5 p 108(12).

7. Bruce Kasanqff. Are you ready for mass customization?. Training, May 1998 v 35, n 5, p 70(7).

8. Ronald SM. Lau. Mass customization: the next industrial revolution. Industrial Management, Sept-Oct 1995 v 37 , n 5 p 18(2).

9. Toby B. Gooley. Mass customization: how logistics makes it happen. Logistics Management A Distribution Report, April 1998, v 37, n 4, p 49(4).

10. Jame H. Gilmore; and B..Ioseph Pine, II. Markets of one: creating customer-unique value through mass customization. Boston, MA02163: Havard Business School Publishing, 2000.

11. B.Joseph Pine, II. Mass customization: The new frontier in Business Competition. Boston, MA02163: Havard Business School Publishing, 1993. 
NOTES 